$01,07,13$

\title{
Динамика морфологии поверхности вольфрамовой фольги под нагрузкой
}

\author{
() В.Е. Корсуков, А.В. Анкудинов, В.И. Бетехтин, П.Н. Бутенко, В.Н. Вербицкий, В.Л. Гиляров, \\ И.В. Гиляров, С.А. Князев, М.М. Корсукова, Б.А. Обидов
}

Физико-технический институт им. А.Ф. Иофрфе РАН,

Санкт-Петербург, Россия

E-mail: vjacheslav.korsukov@mail.ioffe.ru

Поступила в Редакцию 21 мая 2020 г.

В окончательной редакции 21 мая 2020 г.

Принята к публикации 28 мая 2020 г.

\begin{abstract}
Методами дифракции медленных электронов, электронной оже-спектроскопии, атомной силовой микроскопии, сканирующей электронной микроскопии и рентгеновского флуоресцентного анализа исследовалась in situ динамика изменения морфологии поверхности рекристаллизованной фольги вольфрама под воздействием одноосного растяжения. Установлено, что перед разрывом образца переход мультифрактальность-монофрактальность состоит из нескольких стадий: происходит сужение ширины мультифрактального спектра сингулярности поверхностных дефектов, разворот структурных блоков доминирующей грани (112) вольфрама и переход решетки доминирующей грани в дифракционно-неупорядоченное состояние.
\end{abstract}

Ключевые слова: вольфрам, атомная структура, рельеф поверхности, механическое растяжение, предвестники разрыва.

DOI: 10.21883/FTT.2020.12.50202.112

\section{1. Введение}

Изучение влияния температуры и механических воздействий на атомную структуру и рельеф поверхности металлов важно для выяснения механизмов деформации и разрушения, для выявления основных черт гетерогенного катализа, создания новых наноматериалов, а также для других направлений фундаментальной и прикладной физики [1-22].

В предразрывном состоянии происходит переход из мультифрактального состояния поверхности в монофрактальное. Однако переход из мультифрактального в монофрактальное состояние, по нашему мнению, состоит из нескольких стадий.

Для выявления признаков предстоящего разрушения ГЦК- и ОЦК-кристаллов следует обратить внимание на развал атомной решетки, разворот ее блоков, изменение фрактальной размерности и тенденцию перехода из мультифрактального в монофрактальное состояние.

В нашей работе мы надеемся выявить, какие факторы, и в какой последовательности, обеспечивают этот переход.

В настоящее время работы по влиянию нагрузки на морфологию поверхности с использованием мультифрактального подхода широко распространены $[2,3,7,11,14-19]$.

Несомненный интерес представляют подобного рода эксперименты и на металлах с ОЦК-решеткой, поскольку они имеют особый тип дислокационных структур, набор плоскостей скольжения и, соответственно, другие механизмы деформации и разрушения по сравнению с ГЦК-решетками. Первые результаты таких экспериментов на образцах вольфрама представлены в [15].
Целью настоящей работы являлось изучение морфологии (атомной структуры и рельефа) поверхности металла с ОЦК-решеткой (вольфрама) в процессе растяжения и установление признаков предстоящего разрыва. Необходимо выяснить, как под влиянием нагрузки проявляется тенденция к монофрактализации. На каком этапе происходит развал гофров в поверхностном слое. Когда происходит разворот блоков доминирующей грани на поверхности. И, наконец, когда происходит развал атомной структуры доминирующей грани в поверхностном слое. В результате исследования предполагается выявить признаки предстоящего разрыва образцов вольфрама.

\section{2. Материалы и методы исследования}

\section{1. Приготовление образцов}

Исходным материалом в настоящей работе служили поликристаллические фольги вольфрама чистотой $99.96 \%$ и толщиной $20 \mu \mathrm{m}$.

Из фольги вырезались полоски длиной $20 \mathrm{~mm}$, шириной $4 \mathrm{~mm}$, толщиной $20 \mu \mathrm{m}$. Для локализации разрыва в полосках были сделаны вырезы радиусом $15 \mathrm{~mm}$, как это показано на рис. 1, что позволило локализовать место предстоящего разрыва и наблюдать за ним с помощью различных методов.

Поверхность образцов полировалась пастой ГОИ, затем очищалась ацетоном и изопропиловым спиртом с последующей сушкой в сухом азоте. 
Дальнейшая обработка образцов происходила в установках для исследования поверхности твердых тел, где производился рекристаллизационный отжиг, с повторением циклов отжига в сверхвысоком вакууме $(\mathrm{CBB})$ и кислородной атмосфере. Отжиг необходим для получения монокристаллической и атомно-чистой поверхности вольфрама. Отжиг в СВВ происходил при температурах $(1500-1800)^{\circ} \mathrm{C}$, в кислороде при температурах $(1100-1200)^{\circ} \mathrm{C}$, парциальное давление $\mathrm{O}_{2}$ составляло величину $\left(10^{-4}-10^{-6}\right)$ Ра. Более подробно циклический отжиг описан в [15].

\section{2. Примененные методики}

Методики, примененные в работе, можно условно разделить на те, которые работают в СВВ, в вакууме и в атмосфере сухого азота. Во-первых, это дифракция медленных электронов (LEED) и электронная оже-спектроскопия (AES). Во-вторых, метод сканирующей электронной микроскопии (SEM) и метод энергодисперсионной рентгеновской спектроскопии (EDS). B-третьих, атомная силовая микроскопия (AFM) и оптическая микроскопия $(\mathrm{OM})$.

Эти методы позволяют исследовать трансформацию атомной структуры, химический состав и рельеф поверхностного слоя под влиянием нагрузки, вплоть до разрыва образца in situ (смотри рис. 1).

Образцы крепились в зажимах и помещались в СBВ в модернизированных установках фирмы Leybold-Heraeus и Varian, где производились их рекристаллизация и растяжение вплоть до разрыва. При этом состояние атомной структуры и химического состава поверхности контролировалось методами LEED и AES.

После этого часть образцов вынималась из CВВ-установки и исследовалась другими методиками на предмет изменения рельефа и химического состава поверхностного слоя.

При нагружении образцов в сухом азоте использовался атомно-силовой микроскоп „Интегра Аура“, а в вакууме с давлением $P \sim 10^{-3}$ Ра использовали сканирующий электронный микроскоп AIS2300 с приставкой ROVA550i.

При обработке топограмм поверхности использовали фрактальный анализ [7,14-20].

На рис. 1, $a$ представлена схема исследования нагруженной поверхности in situ методами LEED, AFM, AES. На рис. $1, b, c-$ схема исследования поверхности разрыва методами OM, AFM, SEM и EDS. Заштрихованный круг - участок поверхности, где наблюдение производилось по линии $O O^{\prime}$ в CBB методами LEED и AES. Заштрихованный квадрат - участок поверхности, где наблюдение производилось по линии $O O^{\prime}$ методами AFM в атмосфере сухого азота и методами SEM и EDS в вакууме. На рис. $1, b$ показана схема исследования поверхности разорванного образца по линии $O O^{\prime}$ методом AFM. Рис. $1, c$ - схема исследования поверхности

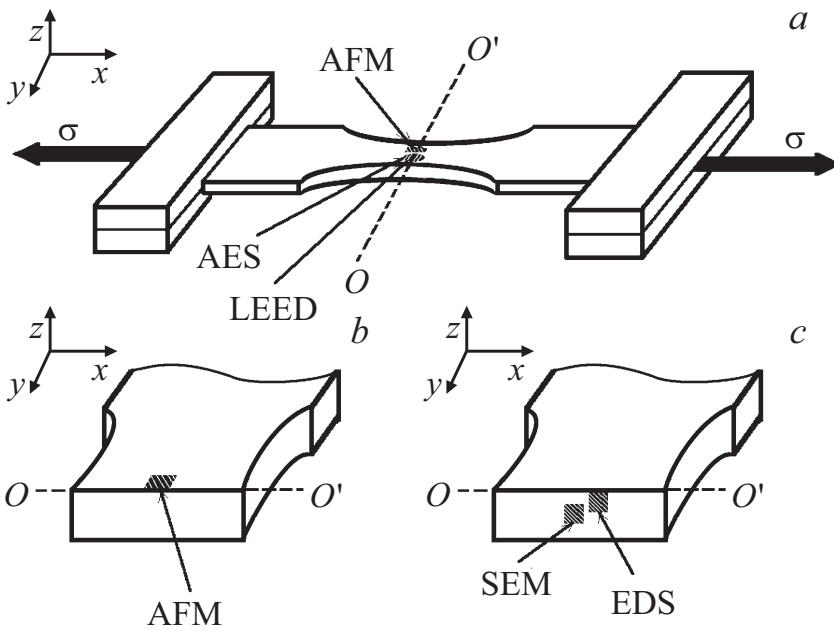

Рис. 1. Образец в зажимах $(a)$ и части разорванного образца $(b, c)$.

разрыва образца в атмосфере сухого азота методами SEM и EDS.

Процесс очистки и рекристаллизации образца состоял из серии циклов прогревов вольфрамовой полоски в вакууме и кислороде. Подробно этот процесс описан в [8]. На конечной стадии подготовки образца в оже-спектрах практически отсутствовали пики углерода.

Размещение устройства для механического растяжения образцов на фланце кристаллодержателя позволило наблюдать за трансформацией картин LEED непосредственно в процессе нагрева и растяжения. Высокотемпературный прогрев образца вплоть до $2100 \mathrm{~K}$ осуществлялся путем пропускания через образец электрического тока от регулируемого источника переменного напряжения. Температура нагретой полоски определялась с помощью пирометра. Напуск кислорода в дифракционную камеру осуществлялся через натекатель.

После рекристаллизации образцов в СВВ часть из них нагружалась в условиях СВВ при контроле методами LEED и AES.

Другая часть образцов вынималась из СВВ и нагружалась в сухом азоте с получением топограмм методом AFM и в вакууме (при давлении $P=10^{-3} \mathrm{~Pa}$ ) с определением химического состава поверхности методом EDS. Размеры исследуемых площадок варьировались от $80 \times 80$ до $1 \times 1 \mu \mathrm{m}$. Образцы нагружались вплоть до разрыва, при этом поверхность разрыва также исследовалась методами AFM и EDS.

Оценка фрактальной размерности поверхности образца в зависимости от нагрузки была проведена методом покрытий („Box Counting“) с использованием программы Gwiddion [15]. Поверхность исследовалась с разрешением $256 \times 256$ и $512 \times 512$ точек в латеральных направлениях, при этом она покрывалась сеткой с кубическими ячейками.

Полученные методом AFM топограммы поверхности исследовались методом мультифрактального ана- 

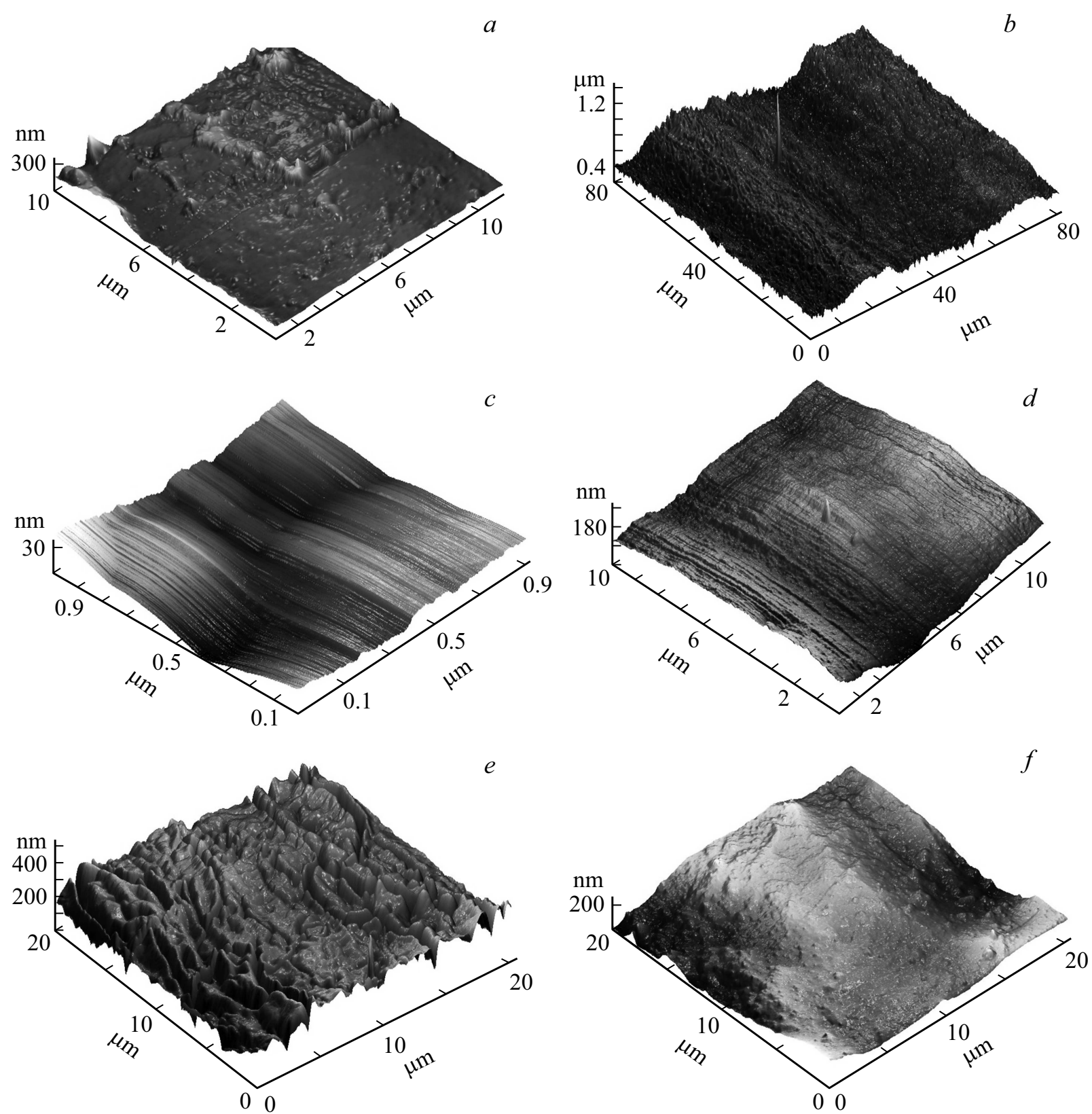

Рис. 2. Рельефы поверхности образцов, подвергнутых различным напряжениям после их рекристаллизации в СВВ: $a-\sigma \approx 0$; $b, c-\sigma \approx 0.9 \mathrm{GPa}, d-\sigma \approx 1.1 \mathrm{GPa}, e-\sigma>1.1 \mathrm{GPa}, f-\sigma=0$ (разорванный образец).

лиза с использованием алгоритма, описанного в [14]. Поверхность разбивалась на квадратные ячейки $N(\varepsilon)$ размером $\varepsilon$. В качестве фрактальной меры выбиралась высота поверхностного профиля $h$. Вероятность заполнения ячейки, обозначенной индексами $i, j$ определялась соотношением:

$$
P_{i j}(\varepsilon)=\frac{h_{i j}}{\sum h_{i j}},
$$

где $h_{i j}-$ средняя высота профиля в ячейке. Высота профиля отсчитывалась от плоскости, смещенной на $1 \mathrm{~nm}$ от минимальной высоты профиля (чтобы исключить нулевые значения в (1)). Вычислялась статистическая сумма

$$
Z(q, \varepsilon)=\sum P_{i j}^{q}(\varepsilon) \sim \varepsilon^{\tau(q)},
$$

которая для мультифрактальных поверхностей обладает скейлингом с экспонентой $\tau(q)$. Скейлинговая экспонента $\tau(q)$ находилась по наклону зависимости $\ln (Z)$ от $\ln (\varepsilon)$. Спектр сингулярностей $f(\alpha)$ рассчитывался из скейлинговых экспонент $\tau(q)$ при помощи преобразования Лежандра:

$$
\alpha(q)=\frac{d \tau(q)}{d q}, \quad f(\alpha)=q \cdot \alpha(q)-\tau(q) .
$$

Из функции $f(\alpha)$ определяется ширина спектра сингулярностей Г. 


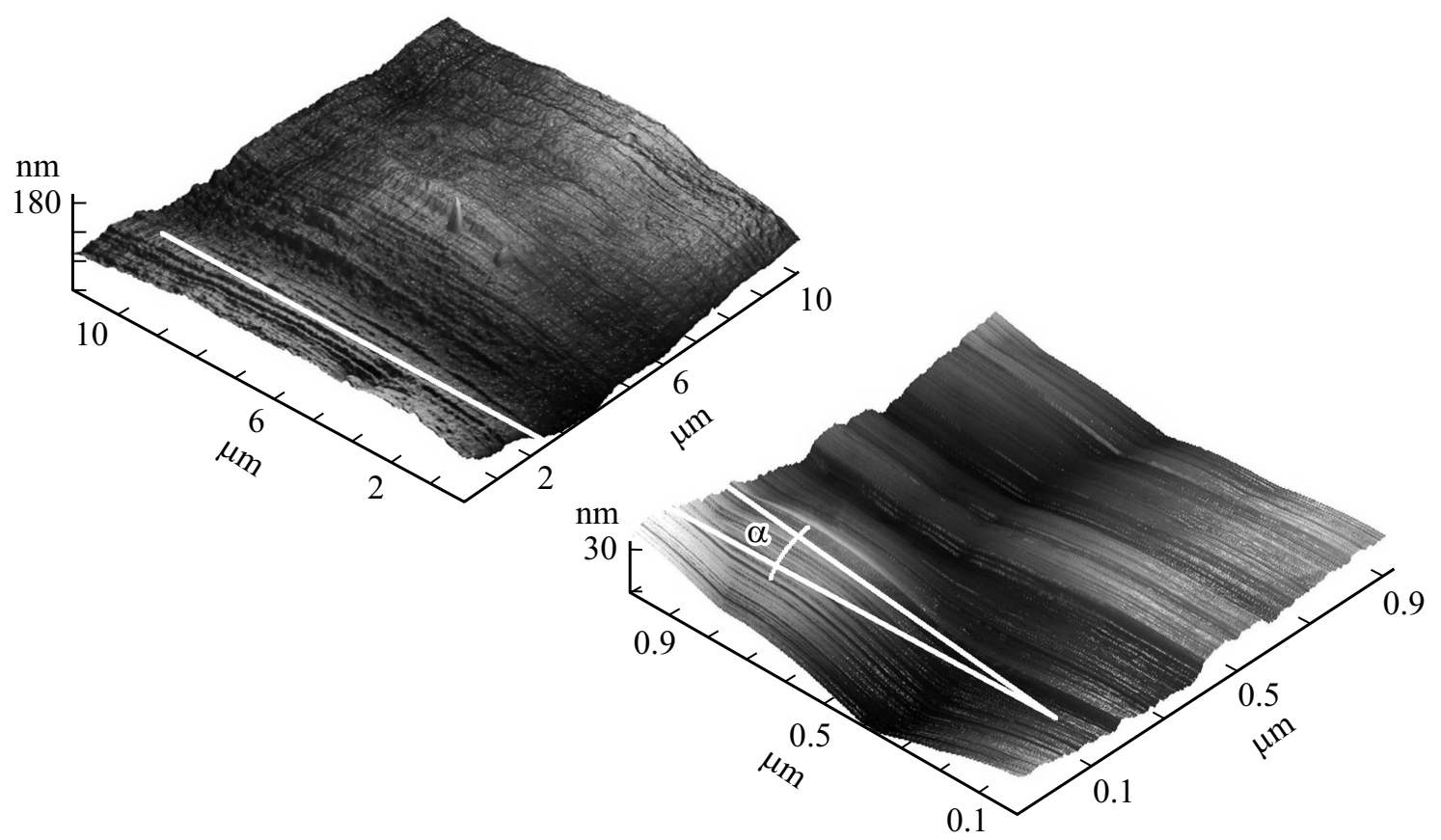

Рис. 3. Разориентация направлений гофров в нагруженном образце при $\sigma \approx 0.94 \mathrm{GPa}$. Слева площадка $(10 \times 10) \mu \mathrm{m}^{2}$, справа площадка $(1 \times 1) \mu \mathrm{m}^{2}, \alpha-$ угол разориентации гофров составляет величину порядка $10^{\circ}$.

\section{3. Результаты и их обсуждение}

\section{1. Влияние растяжения на топограммы поверхности}

Метод AFM был применен к образцам, аналогичным тем, на которых проводились дифракционные исследования. Образец последовательно нагружался от $\sigma=0$ до разрыва, который происходил при напряжении более $1.1 \mathrm{GPa}$. Были получены топограммы поверхности заштрихованной области образца при различных нагрузках, см. рис. 1. Латеральные размеры топограмм поверхностей были $80 \times 80,30 \times 30,10 \times 10$ и $1 \times 1 \mu \mathrm{m}^{2}$.

Было зарегистрировано четыре серии топограмм поверхности: (методом AFM). Первая серия - топограммы без нагрузки после рекристаллизации в СBВ, вторая серия - топограммы поверхности образца, подвергнутого растяжению (разрешение $512 \times 512$ точек), третья серия - топограммы поверхности разорванного образца в различных точках вблизи разрыва (разрешение $512 \times 512$ точек). Четвертая серия повторяет вторую серию, но с меньшим разрешением $(256 \times 256$ точек).

Некоторые из AFM-топограмм поверхности образцов под разными нагрузками представлены на рис. 2.

\section{2. Мультифрактальные спектры сингулярностей поверхности фольги}

Из рис. 2, $a-e$ видно, что, во-первых, несколько систем дефектов различного масштаба накладываются друг на друга. Такие рельефы поверхности характерны для фрактальных структур [15-18]. Во-вторых, на рисунке представлены гофры с различной ориентацией.

На рис. 3 показано различие в направлениях гофров для двух участков поверхности в нагруженном образце при $\sigma \approx 0.9 \mathrm{GPa}$.

Подобные различия в направлениях поверхностных гофров наблюдаются и для других поверхностных площадок.

Отметим, что эти различия играют определенную роль в расшифровке картин дифракции, так же как для поверхностей рекристаллизованных фольг Pt $[18,19]$.

Спектры сингулярностей (СC) были рассчитаны с помощью процедуры, описанной ниже, см. (1)-(3). На рис. 4 приведены СС поверхностных слоев вольфрама, относящиеся к разным участкам поверхности, при различных нагрузках.

Из рисунков видно, что спектры сингулярностей и их ширины зависят не только от нагрузки, приложенной к образцу, но и от места в разорванном образце.

Из зависимостей, приведенных на рис. 4, можно, получить ширины спектров сингулярностей (ШСС) $\Gamma$ и фрактальные размерности поверхностей $-D_{f}$.

Изменения фрактальной размерности и ширин спектров сингулярностей (ШСС) в зависимости от приложенной ступенчатой нагрузки показаны на рис. 5, $a, b$. Из рисунка видно, что фрактальная размерность сначала растет, потом остается практически постоянной, затем для площадки $(10 \times 10) \mu \mathrm{m}^{2}$ уменьшается при приближении к моменту разрыва, а для площадки $(1 \times 1) \mu \mathrm{m}^{2}$ растет. Поэтому $D_{f}$ не может быть признаком предстоящего разрыва. ШСС ведет себя более сложно. 
Г сначала уменьшается, а при формировании магистральной трещины и приближении к разрыву образца снова увеличивается. Последнее увеличение Г объясняется тем, что в область измерения попадает часть
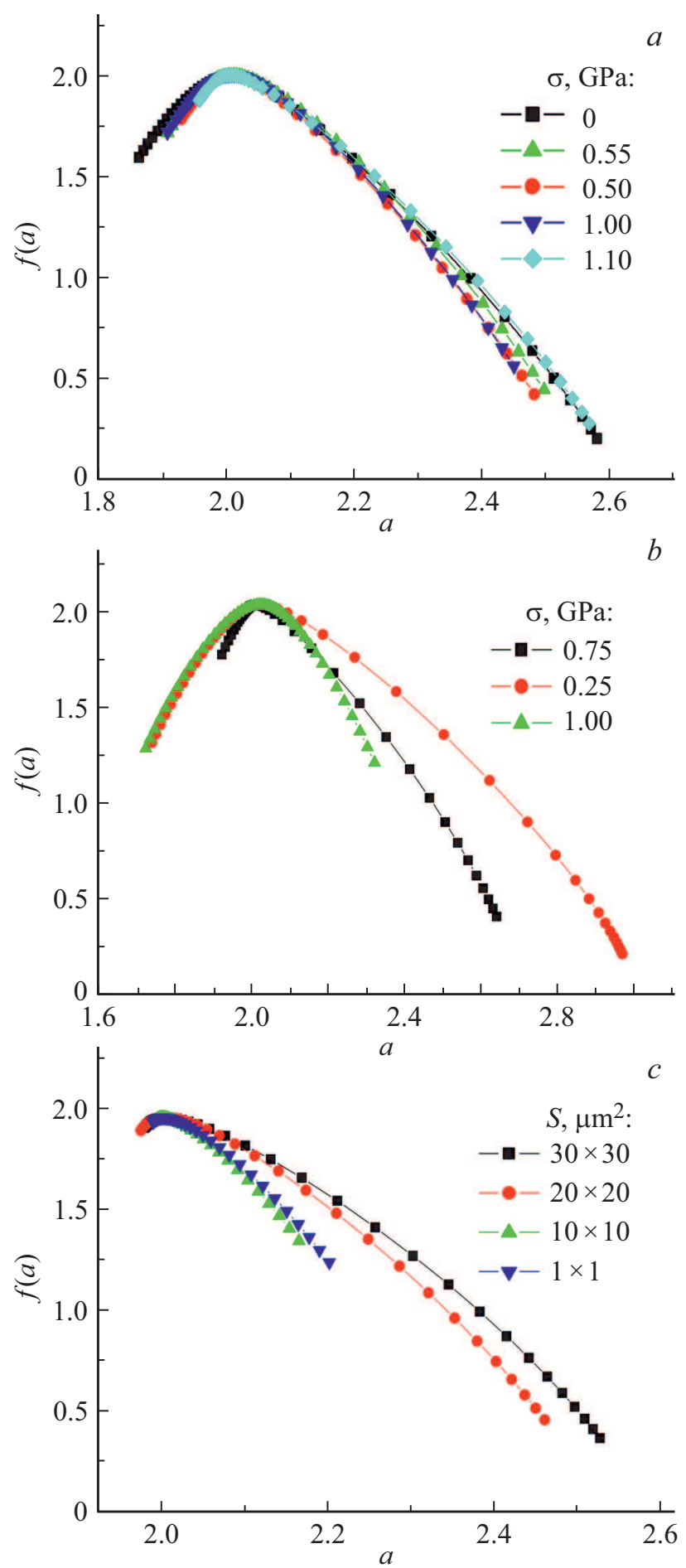

Рис. 4. Рассчитанные спектры сингулярностей $f(\alpha)$ в режиме ступенчатого нагружения: $a-$ площадка $(10 \times 10) \mu \mathrm{m}^{2}, b-$ площадка $(1 \times 1) \mu \mathrm{m}^{2}, c-$ спектры сингулярностей $f(\alpha)$ разорванного образца, измеренные по линии $O O^{\prime}$ (см. рис. 1$)$. На рис. 4,c приведены кривые, соответствующие участкам различной площади $S$. поверхности, содержащей магистральную трещину и разгруженные участки, имеющие увеличенные $Г$.

Уменьшение Г в рамках нелинейной динамики обусловлено изменением характера поведения системы от более сложного к более простому, от мультифрактального к монофрактальному поведению. Фактически реализуется фрактальная самоорганизация системы.

Для того чтобы установить признаки предстоящего разрыва, необходимо сопоставить рельефы нагруженных поверхностей с данными по LEED.

\section{3. Нагружение образцов в СВВ: получение и анализ картин LEED}

В настоящей работе будет сделана попытка сопоставить данные, полученные методом LEED, и топограммы поверхности, полученные методом AFM, в зависимости от нагрузки. В данном случае данные по структуре и по рельефу получены in situ, в отличие от [15].

В нашем случае на конечной стадии рекристаллизации на оже-спектрах практически отсутствовали пики углерода и кислорода. Сопоставление геометрии дифракционной картины с обратной поверхностной решеткой для различных граней показало, что на поверхность рекристаллизованной фольги выходит грань (112) со структурой $1 \times 1$.

В [15] и в настоящей работе (см. рис. 5) показано, что площадка когерентности размером примерно $(0.2 \times 0.2) \mu \mathrm{m}^{2}$ атомно-гладкая. Радиус когерентности электронов в LEED-экспериментах порядка $10 \mathrm{~nm}$, а сечение электронного пучка приблизительно $0.3 \mathrm{~mm}$. Поэтому полная дифракционная картина на люминесцентном экране низковольтного дифрактометра это результат сложения интенсивностей от примерно $10^{8}$ участков поверхности, покрываемых электронным пучком.

На рис. 6, $b$ и 6, $c$ показаны изменения кристаллографических направлений под влиянием нагрузок $\sigma \approx 0.9 \mathrm{GPa}$. Угол $\approx 13^{\circ}$ характеризует существующее различие в направлениях гофров при малых и больших масштабах. Угол $\approx 18^{\circ}$ характеризует временной разворот блока и соответствующее ему совпадение направлений гофров при $\sigma \approx 0.9 \mathrm{GPa}$, когда исчезают различия в направлениях при малых и больших масштабах.

Рис. $6, d$ показывает разрушение кристаллической решетки поверхности.

Были исследованы in situ картины дифракции нагруженной поверхности и топограммы разорванной поверхности на разных расстояниях от места разрыва.

Из зависимости высоты рельефа $Z$ от $X$ в направле-

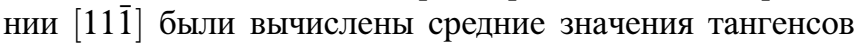
углов наклона участков этих кривых и оценены их углы вблизи разрыва и вдали от него. Рис. $6, b, c$, показывает, что при сравнительно малых нагрузках каждый рефлекс состоит из трех или двух дифракционных максимумов, отстоящих друг от друга приблизительно на $10^{\circ}$. В представленном случае на поверхности вольфрама 

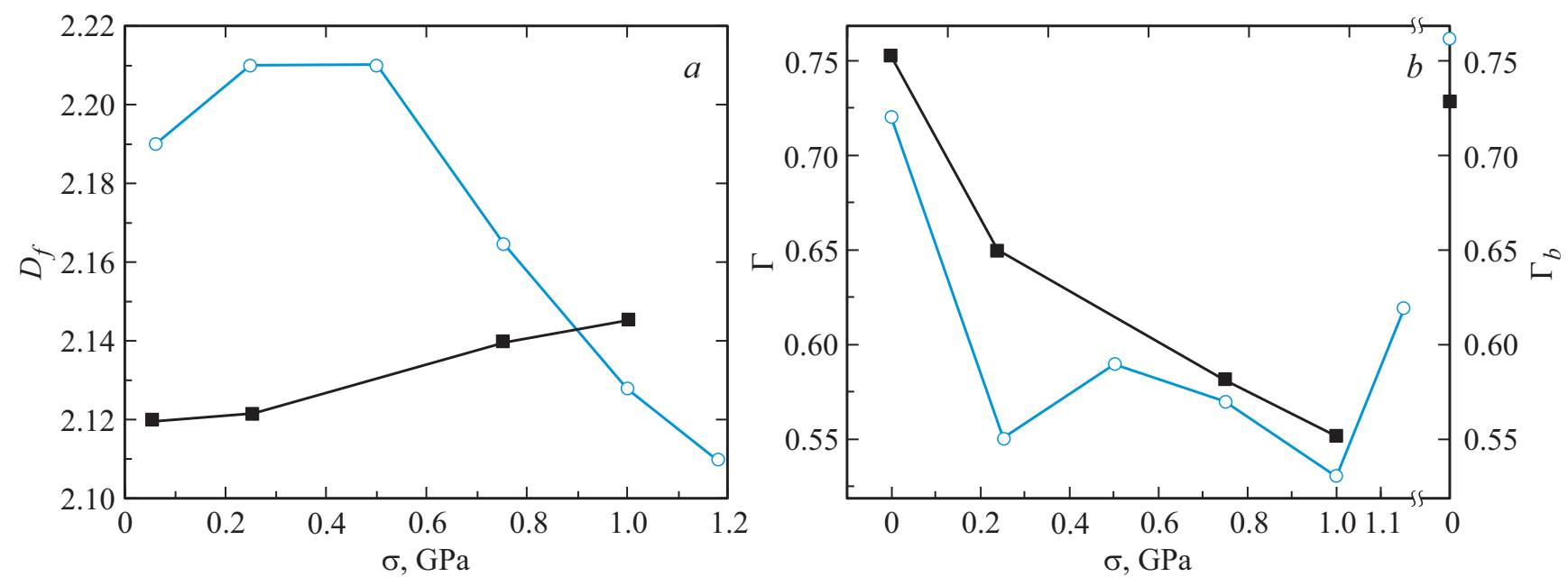

Рис. 5. Зависимость фрактальной размерности $D_{f}(a)$ и ШСС $\Gamma(b)$ от приложенного к образцу напряжения. Светлыми кружками показаны зависимости $D_{f}$ и Г для площадок $(10 \times 10) \mu \mathrm{m}^{2}$, черными квадратами - для площадок $(1 \times 1) \mu \mathrm{m}^{2}$. На правой шкале части $b$ отмечены значения $\Gamma_{b}$ для площадок $(10 \times 10)$ и $(1 \times 1) \mu \mathrm{m}^{2}$ разорванного образца.

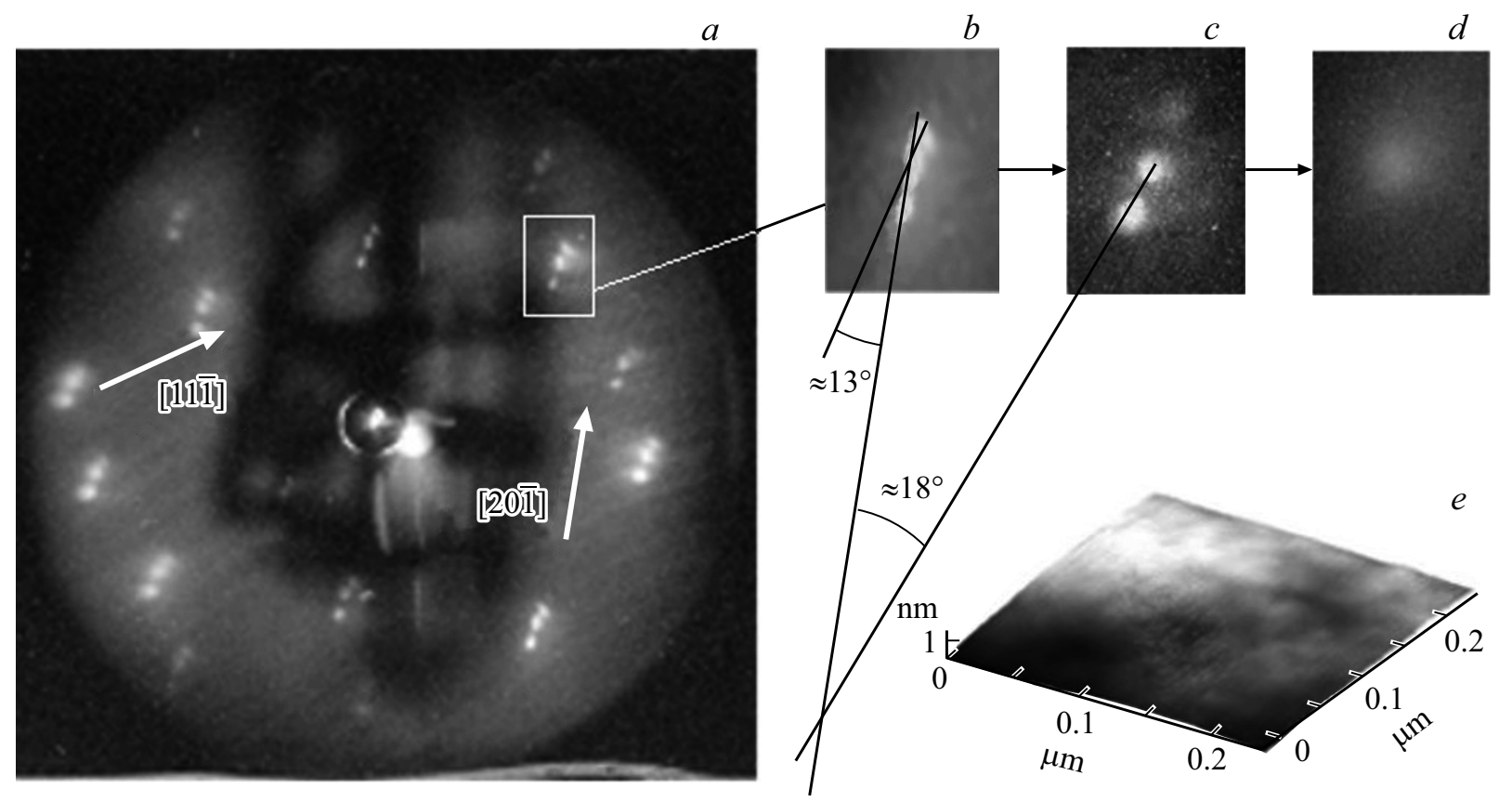

Рис. 6. Изменение картин дифракции рекристаллизованного образца в зависимости от приложенного напряжения: $a$ и $b-$ образец после рекристаллизации в свободном состоянии, $\sigma \approx 0$ (на части $a[11 \overline{1}]$ и $[20 \overline{1}]$ - кристаллографические направления), $c-\sigma \approx 0.9 \mathrm{GPa}, d-\sigma \approx 1.1 \mathrm{GPa}, e-$ площадка когерентности.

реализуются, по крайней мере, два типа периодических структур. Во-первых, на атомном уровне это грань (112) со структурой $1 \times 1$. Во-вторых, крупномасштабная периодичность, проявляющаяся в расщеплении рефлексов, одинаковая по всему сечению анализирующего электронного пучка. При этом направление [11]], являющееся одним из основных для грани (112) вольфрама, отличается от направления механической полировки, вдоль которого вырезались образцы. Крупномасштабная периодичность связана с образованием поверхностных гофров.
В настоящее время мы можем резюмировать, что наибольшее изменение картин LEED наблюдалось в местах предстоящего разрыва, что согласуется с результатами работы [15]. Анализ полученных картин LEED показывает следующее. Картины LEED без нагрузки и картины LEED под нагрузкой вдали от места предстоящего разрыва мало отличались друг от друга. Это означает, что под влиянием растяжения имеющиеся небольшие (на несколько градусов) разориентации гофров доминирующей грани (112) вольфрама относительно направлений $[11 \overline{1}]$ и $[20 \overline{1}]$ исчезают. 

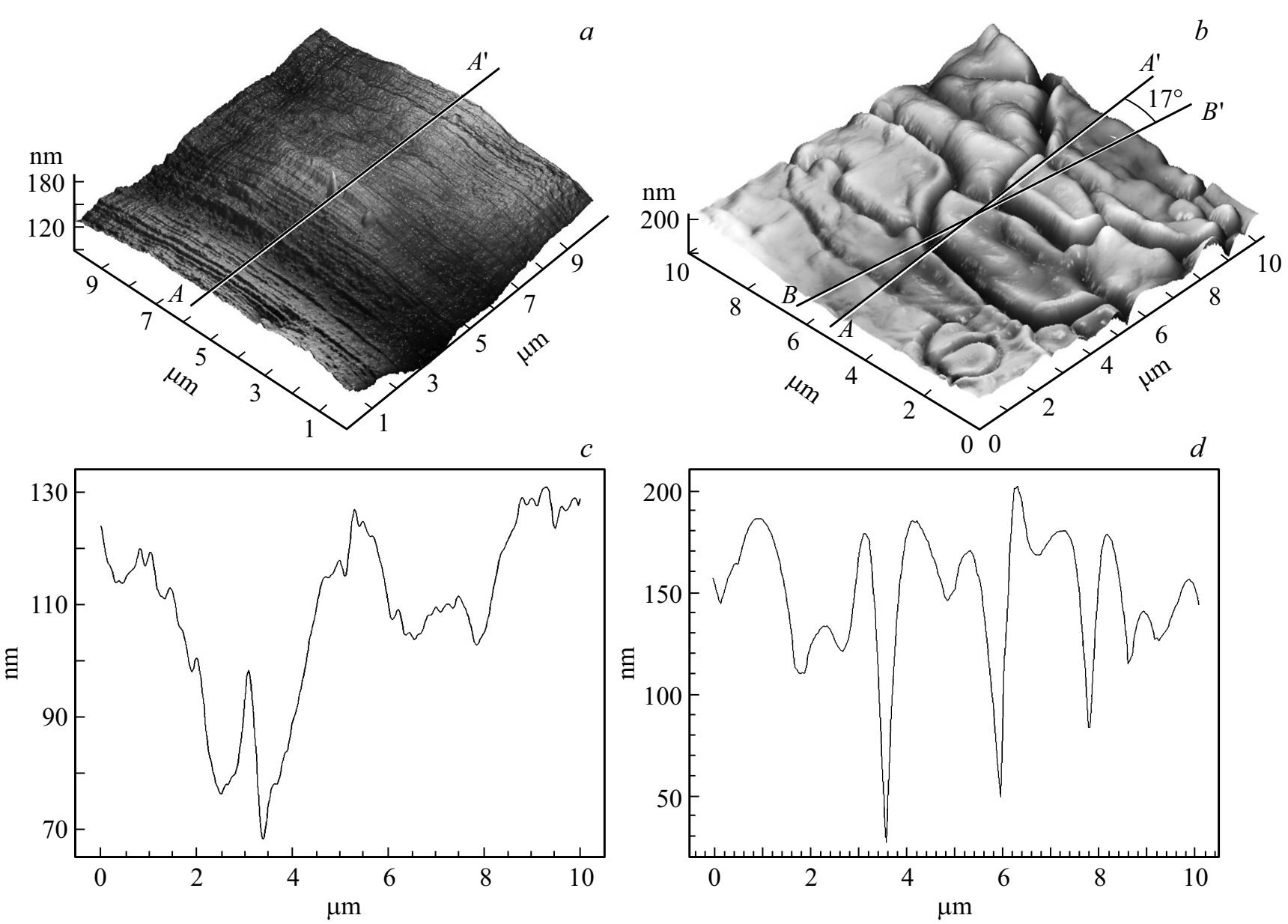

Рис. 7. АFМ-топограммы поверхностей при $\sigma \approx 0.9 \mathrm{GPa}(a)$ и при $\sigma>1.1 \mathrm{GPa}(b)$ и соответствующие им профили сечений $A A^{\prime}$

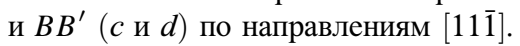

Подобное совпадение направлений гофров, по нашему мнению, можно иллюстрировать схемой разворота дифракционной картины, (смотри рис. 6, $a-c$ ). Видно, что под влиянием нагрузки происходит поворот дифракционной картины, как единого целого, приблизительно на $10^{\circ}$ в направлениях $[11 \overline{1}]$ и $[20 \overline{1}]$. Таким образом, механическое одноосное растяжение привело к изменению „дальнего“ порядка - развороту отдельных блоков в латеральной плоскости и изменению характера периодичности во взаиморасположении этих блоков.

Сопоставим данные LEED с рельефами поверхности в предразрывном состоянии образца (рис. $6, d$ и рис. $2, d$ ). Из сопоставления рисунков видно, что поверхность перешла в дифракционно-неупорядоченное состояние; этому соответствует рельеф, содержащий искаженные гофры (рис. 2, $d$ ), или поверхность без гофров (рис. 2,f).

Отметим сразу же, что и поверхность разорванного образца (рис. 2,f) также не содержит гофров. Это последний момент, который мы зафиксировали перед разрывом.

Влияние нагрузки этим не ограничивается, происходит не только разворот блоков в азимутальном направлении, но и изменение топограмм в вертикальном направлении $Z$. Последнее можно оценить, анализируя профили сечений топограмм образцов под влиянием нагрузки.

На рис. 7 показан разворот доминирующей грани (112) вольфрама под влиянием растяжения; величина и направление разворота взяты из данных LEED. Видно, что рельеф поверхности без гофров развернулся вправо приблизительно на $15^{\circ}$, а остальные профили рельефа поверхности окончательно утратили гофры.

Метод AFM был применен к образцу находящемуся в предразрывном состоянии. Из профилей сечений определены средние тангенсы углов наклона высоты $Z$ в зависимости от $X$ в направлениях $A A^{\prime}$ и $B B^{\prime}$.

Среднее значение тангенсов углов наклона при нагрузке $\sigma>1.10 \mathrm{GPa} \mathrm{в} \mathrm{направлении} A A^{\prime}$ равно приблизительно 0.02 , а среднее значение тангенсов углов наклона при нагрузке $\sigma \approx 90 \mathrm{GPa}$ в направлении $B B^{\prime}$ равно приблизительно 0.01 , т. е. в два раза меньше. Это говорит о том, что в предразрывном состоянии пропадают гофры и рельеф поверхности становится более грубым. Из сравнения рис. $7, a$ и $b$ видно, что направление $A A^{\prime}$ развернулось вправо приблизительно на $15^{\circ}$. 


\section{4. Анализ поверхностей разорванных образцов}

На рис. 8 помещено SEM-изображение $(8, a)$ и спектры EDS поверхности разрыва $(8, b, c)$. На рис. $8, a$ прямоугольниками показаны области (размером приблизительно $15 \times 15 \mu \mathrm{m}^{2}$ ) для которых были получены микрорентгеновские спектры, причем область 1 принадлежит середине области разрыва, а область 2 принадлежит участку, который расположен вблизи первоначальной поверхности образца.

Рис. 6, $d$ показывает, что поверхность перешла в дифракционно-неупорядоченное состояние, при этом рельеф поверхности лишился гофров (рис. 2,e,f).

Подобный эффект можно интерпретировать либо как аморфизацию поверхностных слоев, либо как переход их в нанокристаллическое состояние [15-18].

Из рис. 8 видно, что на поверхности разрыва кроме атомов W содержатся атомы $\mathrm{O}, \mathrm{C}, \mathrm{S}$, и $\mathrm{Zr}$.

Кроме того, рис. 8 показывает, что при воздействии растяжения происходит обогащение поверхности разрыва кислородом, углеродом, а также цирконием и серой.
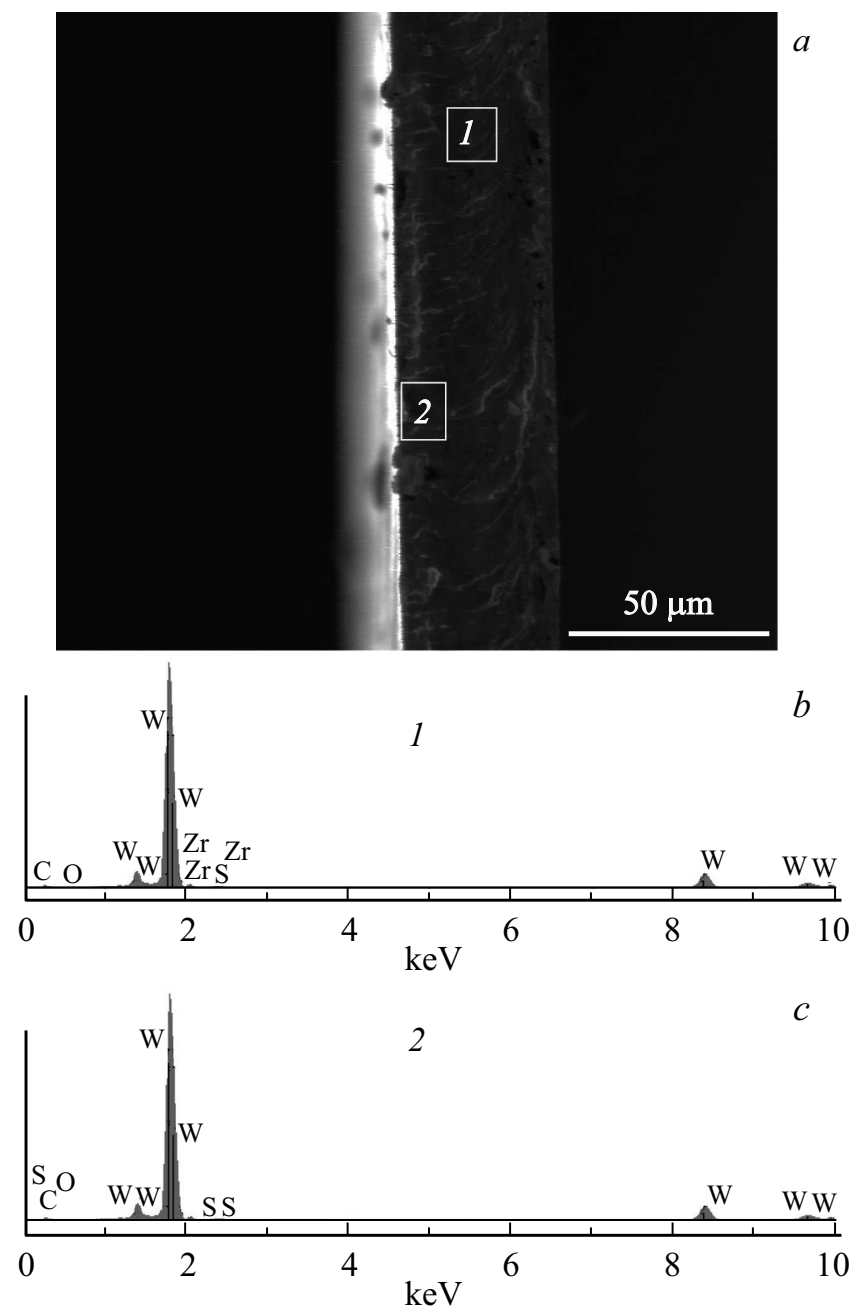

Pис. 8. SEM изображение поверхности разрыва $(a)$ и спектры $\operatorname{EDS}$ от областей $1(b)$ и $2(c)$.
Такое обогащение мы связываем с облегчением диффузии в твердых телах при воздействии механического напряжения [21,22].

Итак, проведенные исследования позволяют утверждать, что переход мультифрактальность - монофрактальность под нагрузкой происходит в несколько этапов.

На первом этапе поверхностный кристаллический слой (см. рис. 2, $a, b)$, образует однонаправленные гофры (рис. 2, $c, d$ ). На втором этапе происходит разворот гофров и их разрушение. При этом сохраняется кристаллическая структура поверхностного слоя. На третьем этапе - перед самым разрывом образца - реализуется разрушение кристаллической решетки поверхности.

Кроме того, зафиксировано обогащение поверхности разрыва примесными атомами $\mathrm{S}, \mathrm{Zr}$, которые остались в объеме после получения вольфрамовых лент.

\section{5. Заключение}

Под влиянием растягивающего напряжения на поверхности рекристаллизованной вольфрамовой фольги наблюдалось образование двух типов разномасштабных периодических структур: на атомном уровне это грань (112) со структурой $1 \times 1$ и более крупномасштабная периодичность, связанная с расщеплением рефлексов, одинаковая по всему сечению анализирующего электронного пучка, т.е. имеющая макромасштабные размеры.

Обнаружено изменение расщепления рефлексов в картинах LEED после нагружения фольг вольфрама, причем максимальное изменение рефлексов происходит непосредственно в месте предстоящего разрыва.

Выявлен разворот дифракционной картины, как единого целого на приблизительно на $15^{\circ}$ при растяжении образца. Это означает разворот блоков плотноупакованной грани в латеральной плоскости на ту же величину.

Наконец, в предразрывном состоянии образца наблюдается полное размытие рефлексов доминирующей грани (112) вольфрама. Это может быть связано как с аморфизацией поверхности, так и с переходом поверхности в нанокристаллическое состояние.

Таким образом, признаками предстоящего разрыва для рекристаллизованных фольг вольфрама являются: изменение расщепления рефлексов и разворот блоков плотноупакованной грани на поверхности с последующим полным размытием рефлексов этой грани. При этом происходит переход поверхностного слоя из мультифрактального в монофрактальное состояние.

Необходимо отметить, что с началом образования магистральной трещины поверхность снова переходит в мультифрактальное состояние.

\section{Финансирование работы}

Исследование выполнено при финансовой поддержке РФФИ в рамках научного проекта № 18-08-00360.

\section{Конфликт интересов}

Авторы заявляют, что у них нет конфликта интересов. 


\section{Список литературы}

[1] В.П. Алехин, О.В. Алехин. Физические закономерности деформации поверхностных слоев материалов. Изд-во МГИУ, М. (2011). 455 с.

[2] Ю.И. Головин. ФТТ 50, 12, 2113 (2008)

[3] Д.В. Лычагин, Е.А.Алфёрова. ФТТ 57, 10, 1981 (2015).

[4] A. Stwertka. A Guide to the elements. Oxford University Press, N. Y. (2002). 247 p.

[5] V.I. Savenko, Yu.P. Toporov, V.V. Chernyshev, A.I. Malkin. Phys. Met. Metallography 118, 11, 1066 (2017).

[6] C. Panigrahy, A. Garcia-Pedrero, A. Seal, D. Rodríguez-Esparragón, N. Kumar Mahato, C. Gonzalo-Martín. Entropy 19, 534 (2017).

[7] F. Wang, Q. Fan, H. Eugene Stanley. Phys Rev. E 93, 042213 (2016).

[8] S. Tălu, S. Stach, T. Ghodselahi, A. Ghaderi, S. Solaymani, A. Boochani, Ż. Garczyk. J. Phys. Chem. B 119, 17, 5662 (2015).

[9] S. Talu, S. Stach, S. Valedbag, R. Bavadi, S.M. Elani, M. Talu. Mater. Sci. Poland 33, 3, 541 (2015).

[10] R. P. Yadav, U.B. Singh, A.K. Mittal, S. Dwivedi. Appl. Phys. A 117, 2159 (2014).

[11] L. Chen, J.L. Fan, H.R. Gong. J. Nanopart. Res. 19, 118 (2017).

[12] M. Antunes, C.A. Perottoni, D. Gouvea, G. Machado, J.E. Zorzi. J. Nanopart. Res. 20, 25 (2018).

[13] S. Bigl, S. Wurster, M.J. Cordill, D. Kiener. Thin Solid Films 612, 153 (2016).

[14] V.E. Korsukov, P.N. Butenko, A.G. Kadomtsev, M.M. Korsukova, V.S. Levitskii, I.A. Nyapshaev, B.A. Obidov. Nanosystems: Physics, Chemistry, Mathematics 9, 1, 58 (2018).

[15] В.Е. Корсуков, С.А. Князев, П.Н. Бутенко, В.Л. Гиляров, М.М. Корсукова, И.А. Няпшаев, Б.А. Обидов. ФТТ 59, 2, 308 (2017).

[16] В.Е. Корсуков, С.А. Князев, А.В. Анкудинов, М.М. Корсукова, Б.А. Обидов. ПЖТФ 40, 6, 35 (2014).

[17] В.Л. Гиляров, В.Е. Корсуков, П.Н. Бутенко, В.Н. Светлов. ФТТ 46, 1, 1806 (2004).

[18] В.Е. Корсуков, С.А. Князев, А.Л. Буйнов, М.М. Корсукова, С.А. Немов, Б.А. Обидов. ПЖТФ 39, 8, 56 (2013).

[19] В.Е. Корсуков, В.Л. Гиляров, М.М. Корсукова, И.В. Гиляров, Б.А. Обидов. XXIII Петербургские чтения по проблемам прочности. СПб (2008).

[20] M. Nasehnejad, M. Cholipour Shahraki, G. Nabiyouni. Appl. Surf. Sci. 389, 735 (2016).

[21] О.В. Клявин, Н.Н. Аруев, Л.И. Деркаченко, Ю.М. Чернов, В.В. Шпейзман. ЖТФ 87, 11, 1756 (2017).

[22] О.В. Клявин, Н.Н. Аруев, Л.И. Деркаченко, В.Ю. Федоров, Ю.М. Чернов, В.В. Шпейзман. ФТТ 58, 4, 692 (2016).

Редактор Е.Ю. Флегонтова 